\title{
The Effectiveness of Mobile Vocabulary Learning Software for Chinese College Students
}

\author{
Chaoying Zhou \\ Foreign Language Department, Yuncheng University, Yuncheng 044400, Shanxi, \\ China \\ *Corresponding author e-mail: shary.chao_007@163.com \\ ABSTRACT. Mobile vocabulary learning is the trend of vocabulary learning \\ nowadays. This paper takes "Youdao Memorizing Words App" in China as an \\ example to make an empirical study on the effectiveness of mobile vocabulary \\ learning software. The results show that students'vocabulary competence improves \\ by using this App. So it is effective to learn English vocabulary by mobile software. \\ Students think that the software helps them most by building their learning habits.
}

KEYWORDS: mobile learning, English vocabulary, Youdao Memorizing Words App, effectiveness

\section{Introduction}

Vocabulary is the basic of English learning. With the development of computeraided language teaching, various mobile software for vocabulary learning is becoming more and more popular. Most scholars have discussed the effectiveness of vocabulary software from a theoretical point of view. The empirical studies on the effectiveness of using mobile software for college students are not many. College students are active mobile software users; this study takes "Youdao Memorizing Words App" in China as an example to make an empirical study on the effectiveness of mobile vocabulary learning software.

\section{Theoretical Basis of Mobile Vocabulary Learning}

The learning procedure of Youdao Memorizing Words App is as following: 1) Build your own word bank or choose a fixed word list (such as word list for TOEFL) as your objective. 2) Choose one option between “too easy”, “know” or “don't know" for the words popping out; your choice will decide the frequency of the word reviewing. 3) Learn words through checking, the checking forms include blank 
filling, choose word's meaning through pronunciation, choose word's meaning through pictures etc. You can set the checking forms you like. 4) The words you learnt will pop out for you to review in time. 5) You can choose to share your learning on any social intercourse app.

Theoretical basis of mobile vocabulary learning include computer assisted language learning (CALL), learning strategy and forgetting curve. Mohan (1992) points out computer assisted vocabulary learning would be the trend of vocabulary teaching in the world. Keegan (2002) says mobile learning is the future of learning. Chamot, O'Malley (2001) divides learning strategies into metacognitive strategies, cognitive strategies and social/affective strategies. Empirical studies show vocabulary learning strategies could predict vocabulary testing score (Wen, 2004). Students apply kinds of learning strategies using Youdao Memorizing Words App. German psychologist Ebbinghaus's famous forgetting curve presents that newlylearned knowledge will be forgotten very quickly. The memory will last longer if people consciously review the learned material. The words reviewing frequency of Youdao Memorizing Words App follows the forgetting curve.

\section{Research Design}

The research purpose is to know the effectiveness of mobile vocabulary learning software. The subjects of this study are 88 sophomore taught by a same teacher in an undergraduate college with 43 students in one class and 45 students in another class. They major in network engineering. The two classes are randomly divided into experimental class and controlled class. Experiment, test and interview are applied as research methods. Before the experiment, the author made an oral survey on students' mobile vocabulary learning software usage. About half of the students have installed some vocabulary learning software before, but few of them could insist on using it for over 2 weeks, so the present study is feasible.

\subsection{Teaching experiment}

Students attend two 2-hour English classes per week. For the controlled class, teacher applies the traditional teaching method. Teacher specifically explains words' meaning and its usage for about 5-10 minutes per class. And students are required to preview and review new words often after the class. Words learning for the experimental class is illustrated as following. Firstly, before the class, students download Youdao Memorizing Words App and apply the functions of the app under the guidance of teacher. Secondly, students preview the text and build their own word bank by adding their personal new words of the text to the word bank. Thirdly, students are required to learn new words by the App for about five minutes each class; teacher will not illustrate words' meaning specifically in the class. Fourthly, teacher encourages students to review words by Youdao Words Memorizing App often and share their learning in the social intercourse app. As a supervisor teacher conducts words dictation to both the two classes regularly. The teaching experiment for experimental group lasts for 8 weeks. 


\subsection{Tests and interviews}

Two vocabulary tests are conducted to students before and after the experiment. The two tests are compiled by the teacher of the two classes. The test includes two types, multiple choice (choose English meaning of the word) and word translation (from English to Chinese), with the former type 30 items and latter 20 items. Most of the checking words are from the learned texts. Test papers are distributed in class and required to be completed within 40 minutes without using tools. All test papers are graded by the author, 2 points for each item with a total of 100 points.

At the end of the experiment, students of the experimental class are randomly selected for interviews to know students' feelings in the use of the App, the evaluation and suggestions of the App etc.

\section{Results and Discussion}

\subsection{Comparison between two groups}

The pre-test is conducted after four weeks' college English learning. The pre-test results of the two groups are presented in Table 1.

Table 1 Comparison between two groups on pre-test

\begin{tabular}{|c|c|c|c|c|c|c|}
\hline & Group & $\mathrm{N}$ & Mean & Std. Deviation & $\mathrm{t}$ & $\mathrm{p}$ \\
\hline \multirow{2}{*}{ Pre-test } & Controlled group & 43 & 74.74 & 10.95 & \multirow{2}{*}{0.429} & \multirow{2}{*}{0.669} \\
\cline { 2 - 5 } & Experimental group & 45 & 73.73 & 11.16 & & \\
\hline
\end{tabular}

As we can see from Table 1, the mean score of controlled group is 74.74 , while the mean score of experimental group is 73.73. SD (standard deviation) of controlled group is 10.95, while SD of experimental group is 11.16. Independent Samples Ttest of the two groups on the pre-test shows $\mathrm{P}=0.669>0.05$, thus the vocabulary performance between controlled group and the experimental group is not obvious before experiment.

After eight weeks' teaching experiment, post-test was processed to all the participants. The results of the post-test are given in Table 2.

Table 2 Comparison between two groups on post-test

\begin{tabular}{|c|c|c|c|c|c|c|}
\hline & Group & $\mathrm{N}$ & Mean & Std. Deviation & $\mathrm{t}$ & $\mathrm{p}$ \\
\hline \multirow{2}{*}{ Post-test } & Controlled group & 43 & 76.37 & 10.43 & \multirow{2}{*}{-2.017} & \multirow{2}{*}{0.047} \\
\cline { 2 - 5 } & Experimental group & 45 & 80.67 & 9.53 & & \\
\hline
\end{tabular}

From Table 2, the mean score of controlled group is 76.37, while the mean of experimental group is 80.67 . The SD is 10.43 and 9.53 respectively. Independent Samples T-test of the two groups shows $\mathrm{P}=0.048<0.05$. So significant differences 
exist between the two groups, experimental group performs better than controlled group on post-test.

\subsection{Comparison between two tests}

In order to know the effectiveness of the vocabulary learning software for each specific group, paired-samples $\mathrm{T}$ test is conducted between the pre-test and post-test for each group. Table 3 shows the comparison between the two tests for controlled group. The results show $\mathrm{p}=0.000<0.05$, so there is significant difference for controlled group after 8 weeks' college English learning.

Table 3 Comparison between two tests for controlled group

\begin{tabular}{|c|c|c|c|c|c|c|}
\hline & Tests & $\mathrm{N}$ & Mean & Std. Deviation & $\mathrm{t}$ & $\mathrm{p}$ \\
\hline \multirow{2}{*}{ Controlled group } & Pre-test & 43 & 74.74 & 10.95 & \multirow{2}{*}{-4.867} & \multirow{2}{*}{0.000} \\
\cline { 2 - 7 } & Post-test & 43 & 76.37 & 10.43 & & \\
\hline
\end{tabular}

Similarly, paired-samples $\mathrm{T}$ test is also operated between the pre-test and posttest for experimental group, and the results are presented in table 4 . The $\mathrm{P}$ value is 0.000 , it means after the experiment, the experimental group made a remarkable progress on vocabulary tests.

Table 4 Comparison between two tests for experimental group

\begin{tabular}{|c|c|c|c|c|c|c|}
\hline & Tests & $\mathrm{N}$ & Mean & Std. Deviation & $\mathrm{t}$ & $\mathrm{p}$ \\
\hline \multirow{2}{*}{ Experimental group } & Pre-test & 45 & 73.73 & 11.16 & \multirow{2}{*}{-15.979} & \multirow{2}{*}{0.000} \\
\cline { 2 - 5 } & Post-test & 45 & 80.67 & 9.54 & & \\
\hline
\end{tabular}

\subsection{Interview feedback}

After the experiment, the author interviews 8 students randomly from experimental group. Their opinions are summarized. Firstly, they hold positive appraisal for the Youdao Memorizing Words App. Secondly, they think the App benefits them most by helping creating words learning habits for them. Thirdly, in contrast of their traditional words learning, the app is distinctive in the wordschecking function, picture memorizing, review reminding as well as building personal word bank which fits their own learning. Fourthly, it is hard for them to insist on using the app if teacher doesn't urge them often. Fourthly, for the suggestions of the app, they think some of the example sentences are not idiomatic; some of the pictures of the words are not striking enough to make the words unforgettable, and they prefer other words memorizing apps. 


\section{Conclusion}

By taking "Youdao Memorizing Words App” as an example, the research proves the effectiveness of mobile vocabulary learning software. Both of the controlled group and experimental group make progress on vocabulary after 8 weeks of college English learning, but the experimental group make greater progress and their posttest results are significant better than controlled group. Most of students think highly of the app and they are willing to use it in their future study.

\section{References}

[1] Chamot, O’Malley. Learning Strategies in Second Language Acquisition [M]. Shanghai: Shanghai Foreign Language Education Press, 2001

[2] Mohan, B. Models of the Role of the Computer in Second Language Development [A]. In M. Pennington and V. Stevens (eds.) Computers in Applied Linguistics: An International Perspective [C]. UK: Multilingual Matters Ltd, 1992 (2): 110-126.

[3] Keegan D. The future of Learning: From e-Learning to m-Learning. Monographie [J]. 2002.

[4] Wen Qiufang \& Wang Lifei. A Review of Empirical Studies of English Learning Strategies in China for 20 years. Foreign Lanaguage and Literature Studies. [J], 2004.

[5] Ebbinghaus, H. On Memory [M]. New York: Teacher’s College. 1913. 